\title{
Life Cycle Comparative Analysis of Sexual Function in Women with Normal and Overweight Body Mass Index
}

\author{
Cibele Nazaré da Silva Câmara*, Hellen Vivianni Veloso Corrêa, \\ Susanne Cristine Brito e Silva, Caio Santos Alves da Silva, Mauro Silva Junior, \\ Regina S. Brito \\ Post-Graduation Program in Theory and Behavior Research, Federal University of Para, Belém, Brazil \\ Email: ${ }^{*}$ cibelecamara@hotmail.com
}

Received 26 May 2014; revised 30 June 2014; accepted 10 July 2014

Copyright (C) 2014 by authors and Scientific Research Publishing Inc. This work is licensed under the Creative Commons Attribution International License (CC BY). http://creativecommons.org/licenses/by/4.0/

(c) (i) Open Access

\section{Abstract}

Sexual health is considered of fundamental importance in people's lives. Since it is determined by physiological, psychological and social factors, the investigations of these aspects are relevant to full comprehension of this phenomenon. Endocrinological conditions, as overweighed and normal body mass indexes were addressed as the main factors in women' sexual function, which can affect level of sexual hormones; and as a consequence, lead to sexual dysfunction. Body mass index of 370 women were analyzed to indentify the implications in their sexual life, using the Female Sexual Function Index (FSFI) inventory, with six domains that assess different aspects of women' sexual activity and satisfaction. The main results show no statistical differences between normal and overweighed body mass index. However, there were significant differences between different phases of life as Reproductive, Perimenopause, and Postmenopause women, in which the youngsters showed better FSFI scores, better sexual function, than the older ones. Also, significant differences were found when time of marriage was taken into account, the longer the relationship, the worse the sexual function. We concluded that not only endocrinological variables may explain the sexual function in women, but also psychosocial variables as age, and time and quality of their relationships.

\section{Keywords}

Sexual Function, Overweight, Relationship

\footnotetext{
*Corresponding author.
} 


\section{Introduction}

Sexual health is considered of fundamental importance to the longevity of affective relationships and it is seen as one of the factors that help the occurrence, recovery and maintenance of well-being and overall good health of the individual (Mulhall, King, \& Hvidsten Glina, 2008). Initially human sexual response was defined as a four-phasic phenomenon, consisting of: desire, arousal, orgasm and resolution; later on Kaplan (1981) reformulated this model to a triphasic phenomenon, consisting of: desire, arousal and orgasm. Therefore, a sexual dysfunction involves a change in one or more phases of the sexual response cycle or the pain associated with the intercourse, which manifests itself in a persistent or recurrent way (Abdo \& Fleury, 2006).

Results of the National Health and Social Life survey, held in the United States in 1999, show that from a total of 1749 women and 1410 men aged between 18 and 59 years, the most common victims of sexual dysfunction were women (43\%) compared to men (31\%) (Laumann, Paik, \& Rosen, 1999). In the Brazilian literature, similar studies have also found a high incidence of sexual dysfunction among women. In a study conducted in 18 Brazilian cities, 3148 women aged between 18 and 70 years were surveyed; 51\% of them reported some sexual dysfunction (Abdo, 2004). In another study (Mendonça, Silva, Arrudai, García-Zapata, \& Amaral, 2012) half of the women reported at least one sexual dysfunction; $26.7 \%$ reported a lack of sexual desire and $23.1 \%$ reported pain during intercourse; in a cross-sectional study of 100 women aged from 20 to 39 years, the results also showed that $36 \%$ of them reported some sort of sexual dysfunction (Ferreira, Souza, \& Amorin, 2007).

Barroqueiro, Araujo, and Garcia (2012) point out that a few studies investigate sexual function among overweight and obese women (in which the body mass index is equal to or higher than 30 and 25, respectively). The body mass index is the ratio between weight in kilograms and the square of the body height in meters $\left(\mathrm{kg} / \mathrm{m}^{2}\right)$ (Lagergren, Mattsson, \& Nyrén, 2014). The study mostly investigated only the sexual difficulties related to obesity. The study of sexual function of these women is important once this condition is associated with a higher prevalence of metabolic disorders, including depression and sexual dysfunction (Morotti et al., 2012; WHO, 2014).

Overweight and obesity are defined as abnormal or excessive fat accumulation that may impair health and have the potential to promote sexual dysfunction through several mechanisms, by increasing the weight on the pelvic floor muscles, changing its function, change in body image related to the self-perception of sexual attractiveness and depression (Huang, Stewart, Hernandez, Shen, \& Leslee, 2009). Moreover, endocrinological studies argue that the obese adult women produce sex hormones in excess, which increase both sexual desire and sexual functioning (Morotti et al., 2012).

The studies' results on the correlation index of sexual function among overweight and obese women are contradictory, some of the studies have not found good levels of sexual function among these women (Erenel \& Kiline, 2013) differently to (Bajos, Wellings, Laborde, \& Moreau, 2010). Studies that show lower sexual function contradicts the literature that asserts that overweight and obese women produce sex hormones in excess (Morotti et al., 2012). The results of such studies as Erenel \& Kiline (2013) show that the rates of sexual function among overweight and obese women are not as high as they were expected to be according to the levels of circulating sex hormones, unless other variables are influencing these responses. In a study in which the Female Sexual Function Index (FSFI) questionnaire was used to determine the prevalence of sexual dysfunction in obese women, $43 \%$ of them stated that the excess weight had damaged their sexual life, $13 \%$ of participants had a severe sexual dysfunction, in all domains of sexual function (sexual desire, sexual arousal, vaginal lubrication, orgasm, sexual satisfaction, and pain) and showed impaired function (Erenel \& Kiline, 2013). Also, in the study by Vilas-Boas Sartori, Souza and Carneiro (2011) weak correlation between the ability to contract the pelvic floor muscles and the degree of obesity was found, indicating that the degree of obesity cannot influence the ability of pelvic floor contraction. This may imply that other variables have an effect on sexual function in obese women.

So, what would be the consequences of overweight and obesity in female sexual response? Is it possible that factors other than excessive sex hormones are affecting the differences found related to female sexual function among overweight and obese women?

It is possible that overweight and obese women have a favorable hormonal modulation for a good sexual function, however, a woman may present sexual dysfunction due to other factors, such as altering perception of body image distorted from the social impositions, the cultural characteristics of countries where sexuality is seen as a taboo, the quality and length of relationship and others (Erenel \& Kiline, 2013; Liu, 2003).

Human sexual behavior, despite being influenced by current contextual variables, has a phylogenetic history 
that has evolved with our species, and independent of culture, it presents key components to maintaining loving relationships even in the current environment (Buss \& Shakelford, 2008; Fisher, 2004; Gangestad, Haselton, \& Buss, 2006; Lippa, 2007). Fisher (1998, 2000, 2004) proposed that a set of adaptations or neural systems were selected in ancestral environments, which have contributed to the survival and reproduction of our species, namely: lust, romantic relationship and attachment. Lust is the stage in which there is the desire for pleasurable sexual experiences and makes the individual seek to engage sexually with another (Fisher, 1998, 2000, 2004). Then there is the stage of passion, which lasts on average 36 months, the main feature of this system is the concentration of power in the partner characterized by obsessive thoughts and anxiety of separation, reducing the risk of sexual or amorous infidelity (Fisher, 1995, 2004; Marazziti Rossi \& Cassano, 1999, Retry, 1979). According to Fisher (2004), in the passion stage there is an excess of dopamine which stimulates testosterone production, increasing desire. In the other words, it maybe stimulates couples in love and therefore in a more recent relationship less likely to have sexual dysfunction. However, after the passion stage some couples can get to the third system. The attachment system, which is responsible for the sense of security and closeness in a loving relationship, is marked by the need for the presence and company of the mate.

In the absence of cultural restrictions, most of relationships may have an end before they reach the second system, attraction. However, in most societies there exist a set of rules to keep the couples together until later life of death of one of the spouses, even in the lack of mutual interest. When relationships are held by cultural forces rather than by individual's will, we may ask if sexual dysfunction found in many studies can be attributed to those forces instead of individual's psychological or physiological problems.

Thus, despite the high incidence, it is very complex to determine the cause of sexual dysfunction, because sexuality is probably a multidimensional phenomenon associated with biological, psychological, socio-cultural and interpersonal determinants (Piassaroli, Hardy, Andrade Ferreira, \& Osis factors, 2010). As discussed above, there are still discrepancies in the literature about the presence of sexual dysfunction in overweight women and the variables that influence this response. Therefore, the present study aimed to determine and compare the rate of sexual function at different stages of life as well as the length of the relationship between overweight women and women with normal body mass index.

\section{Methods}

\subsection{Participants}

This study has been approved by Human Research Ethics Committee registered under protocol 116/10. It is characterized by being analytical and comparative. The data collection was held at the Santa Casa de Misericordia of Pará Hospital, in Belém city. 370 women aged 18 - 70 years participated, mean age of 43.97 years (SD $=12.48)$. The participants were analyzed considering their body mass index: Normal BMI $(\mathrm{N}=231)$ and overweight BMI ( $\mathrm{N}=132$ ), Age: 18 - 39 years (reproductive age) $\mathrm{n}=114,40$ to 50 years (Perimenopause) $\mathrm{n}=125$, $51-70$ (post menopausal) $n=129$, and length of relationship: 0 - 5 years $(\mathrm{N}=57), 6-10$ years $(\mathrm{N}=38), 11-19$ years $(\mathrm{N}=46), 20$ to 29 years $(\mathrm{N}=75)$ and $30-52$ years $(\mathrm{N}=68)$.

The inclusion criteria were women with a BMI (Body Mass Index) higher or equal to 25, heterosexual, in a stable relationship for more than six months, sexually active with children. Women taking antihypertensive, antidepressants (Brill, 2004), women with prior hysterectomy (Sousa, Sousa, \& Silva, 2000), who have had surgery reconstruction of the pelvic floor (perineoplasty) and neurological damages that may compromise the sexual response were excluded from the study.

\subsection{Instruments}

In order to assess the sexual function of the participants, the FSFI questionnaire-developed in the US, and translated to the Portuguese language, was applied. The scale has good psychometric evaluation, including studies of reliability, validity and convergence of discrimination and a 19-question-questionnaire developed to be self-applied which proposes to assess female sexual response, all multiple choice grouped into six domains: desire, arousal, lubrication, orgasm, satisfaction and pain. The scores of the subscales are corrected and added, making a final score ranging from 2 to 36. Higher scores indicate a degree of better sexual function (Hentschel, Alberton, Capp, Goldim, \& Passos, 2007). Based on the analysis of sensitivity and specificity, Wiegel, Meston, and Rosen (2005) found an FSFI total score of 26.55 to be the optimal cutoff point to differentiate women with and without sexual dysfunction. 


\subsection{Procedure}

Initially, the participants were told about the objectives of the study before requesting for their free and informed consent; the BMI of the participants were calculated according to the criteria proposed by Kopelman (1994), we applied the Female Sexual Function Index questionnaire (FSFI) and in addition, the social demographic data collect from a semi-structured questionnaire.

\subsection{Data Analysis}

Both Student's $t$ test and one-way ANOVA were performed when appropriate. In further analyzes the non-parametric Mann-Whitney and Friedman tests were used instead. Post hoc tests were applied when appropriate, using the Games-Howell correction for multiple comparisons. Initially, women were grouped into Normal BMI and BMI Overweight. Due to the breadth of the age of women in the sample, we established three age groups, 18 - 39 years (Reproductive), 40 - 50 years (Perimenopause) and 51 - 70 years (post-menopausal) (Table 2). Finally, the last grouping criteria correspond to the length of marriage. The average length of marriage was 18.59 years $(\mathrm{SD}=.73)$, however the magnitude of relationships was less than 1 year to 52 years. For this reason, women were grouped into five groups of length of relationship. The following groups were created, 0 - 5 years, 6 - 10 years, 11 - 19 years, 20 - 29 years and 30 - 52 years (Table 3).

\section{Results}

\subsection{Socio-Demographic Assessment}

132 overweight women answered the Female Sexual Function Index (FSFI) questionnaire. Their ages ranged between 20 and 66 years with an average of 49.18 years (13.6\% were 60 years and the remainder of the sample was variable) $(\mathrm{SD}=10.03)$, and $89.4 \%$ were over 40 years. The majority of participants, $47.5 \%$ had completed high school and 35.8\% were graduated or post-graduated. 58.2\% of participants have been married for over 21 years, $12.3 \%$ have been married for five years, $13.1 \%$ have been married for $6-10$ years and $16.4 \%$ have been married for 11 - 20 years. 78.7\% of women said they did not find sexual satisfaction outside marriage, while $12 \%$ reported to find a lot or quite sexual satisfaction outside the marriage $(\mathrm{N}=75)$. In this group the mean of total score and Sexual Function Index was 26.35 (SD = 5.7).

231 women with normal body mass index answered the Female Sexual Function Index (FSFI) questionnaire. The ages of these women ranged between 19 and 70 years, with an average of 40.84 years, and $57.2 \%$ were above 40 years. Most participants, 51\% were graduated or post graduated and $36.6 \%$ had finished high school ( $\mathrm{N}=145$ for education). $37.4 \%$ of participants have been married for more than 21 years and $26.5 \%$ have been married for five years, $12.9 \%$ have been married for 6 - 10 years, and $23.2 \%$ for 11 - 20 years. $81.9 \%$ of women said they did not find sexual satisfaction outside marriage, while 3.9\% reported finding a lot or quite sexual satisfaction outside the marriage $(\mathrm{N}=105)$. In this group the average of total score and Sexual Function Index was 27.37 (SD = 5.28).

Analysis of Sexual Function Index (FSFI)

Table 1 shows scores for each FSFI domain and FSFI total for normal and overweight groups.

Table 1. FSFI mean scores for each domain and group, and total score.

\begin{tabular}{|c|c|c|c|c|c|c|c|c|c|c|c|c|c|c|}
\hline & \multicolumn{2}{|c|}{ Desire } & \multicolumn{2}{|c|}{ Aurousal } & \multicolumn{2}{|c|}{ Lubrication } & \multicolumn{2}{|c|}{ Orgasm } & \multicolumn{2}{|c|}{ Satisfaction } & \multicolumn{2}{|r|}{ Pain } & \multicolumn{2}{|r|}{ Total } \\
\hline & Normal & Overweight & Normal & Overweight & Normal & Overweight & Normal & Overweight & Normal & Overweight & Normal & Overweight & Normal & Overweight \\
\hline $\mathrm{N}$ & 231 & 132 & 231 & 132 & 231 & 132 & 231 & 132 & 231 & 132 & 231 & 132 & 231 & 132 \\
\hline Mean & 3.94 & 3.69 & 4.37 & 4.18 & 4.71 & 4.35 & 4.65 & 4.53 & 4.92 & 4.85 & 4.76 & 4.74 & 27.37 & 26.35 \\
\hline Minimum & 1.2 & 1.2 & 1.2 & 1.2 & 1.2 & 1.8 & 1.2 & 1.2 & 1.2 & 1.2 & 1.2 & 1.2 & 12.2 & 10.1 \\
\hline Maximum & 6.0 & 6.0 & 6.0 & 6.0 & 6.0 & 6.0 & 6.0 & 6.0 & 6.0 & 6.0 & 6.0 & 6.0 & 36.0 & 36.0 \\
\hline
\end{tabular}




\subsection{BMI Effects on Sexual Response}

Based on previous studies that indicated differences in FSFI of women in normal and overweight conditions, woman's age and length of marriage, analyzes were performed taking into account these three variables. However, in this study, no significant differences were found among women in normal and overweight conditions, except for the sex drive and lubrication domains, but not the general score (Desire: $\mathrm{t}_{361}=2.110, p=.036$; Excitement: $\mathrm{t}_{361}=1.692, p=.091$; Lubrication: $\mathrm{t}_{361}=2.840, p=.005$; Orgasm: $\mathrm{t}_{361}=.898, p=.370$; Satisfaction: $\mathrm{t}_{361}=.540, p=.590$; Pain: $\mathrm{t}_{361}=.079, p=.937$; FSFI: $\mathrm{t}_{361}=1.712, p=.088$ ). Considering the results, women in overweight and normal conditions were considered in the same group, so they were analyzed considering their age and length of marriage.

\subsection{Age Effects on Sexual Response}

Due to the breadth of women age in the sample, we established three age groups, 18 - 39 years (Reproductive), 40 - 50 years (Perimenopause) and 51 - 70 years (post-menopausal).

Women in the three age conditions (Table 2) differed significantly in all domains in both general and FSFI score, except for the area of pain (Desire: $F_{2,365}=12.822, p=.001$; Excitement: $F_{2,365}=27.832, p=.001$ Lubrication: $\mathrm{F}_{2,365}=15.145, p=.001$; Orgasm: $\mathrm{F}_{2,365}=4.904, p=.008$; Satisfaction: $\mathrm{F}_{2,365}=9.166, p=.001 ;$ Pain: $\mathrm{F}_{2}$, $365=2.658, p=.071$; FSFI: $\mathrm{F}_{2,365}=17.164, p=.001$ ). The Games-Howell statistic was used for multiple comparisons finding significant differences between all comparisons except for the Score of Orgasm for Reproductive and Perimenopause groups; score of satisfaction, groups Perimenopause and Post-Menopause. By analyzing each age group separately in normal and overweight conditions no significant differences were found.

\subsection{Effects of the Length of Relationship on Sexual Response}

The mean length of marriage was 18.59 years $(\mathrm{SD}=.73$ ), however the magnitude of relationships was less than 1 year to 52 years. For this reason, women were grouped into five groups of length of relationship. The following groups were created, 0 - 5 years, 6 - 10 years, 11 - 19 years, 20 - 29 years and 30 - 52 years (Table 3). Except for the satisfaction domain, there were significant differences between the FSFI domain scores and the overall score according to the length of marriage (Desire: $\mathrm{F}_{4,279}=3.505, p=.008$; Excitement: $\mathrm{F}_{4,279}=4.837, p$ $=.001$; Lubrication: $\mathrm{F}_{4,279}=2.778, p=.027$; Orgasm: $\mathrm{F}_{4,279}=2.744, p=.008$; Satisfaction: $\mathrm{F}_{4,279}=.880, p$ $=.476$; Pain: $\mathrm{F}_{4,279}=3.361, p=.01$; FSFI: $\mathrm{F}_{4,279}=4.393, p=.002$ ). The Games-Howell test identified significant differences in the desire score and arousal, only in the group of 0 - 5 years and groups of 20 - 29 years and 30 - 52 years, in the satisfaction and general FSFI score between the group of 30 - 52 years and groups of 0 - 5 years and 11 - 19 years; Orgasm score between groups 11 - 19 years and 30 - 52 years. By analyzing each length of marriage group separately in normal and overweight conditions no significant differences were found.

Table 2. Scores by age of desire, arousal, lubrication, orgasm, satisfaction and pain areas, and overall FSFI score.

\begin{tabular}{|c|c|c|c|c|c|c|c|c|}
\hline & & Desire & Aurousal & Lubrication & Orgasm & Satisfaction & Pain & FSFI \\
\hline \multirow{4}{*}{18 - 39 years } & $\mathrm{N}$ & 114 & 114 & 114 & 114 & 114 & 114 & 114 \\
\hline & Mean & 4.226 & 4.781 & 5.01 & 4.786 & 5.2211 & 4.912 & 28.937 \\
\hline & Std. Error of Mean & .095 & .09 & .094 & .097 & .094 & .106 & .411 \\
\hline & Std. Deviation & 1.023 & .97 & 1.008 & 1.044 & 1.008 & 1.139 & 4.39 \\
\hline \multirow{4}{*}{40 - 50 years } & $\mathrm{N}$ & 125 & 125 & 125 & 125 & 125 & 125 & 125 \\
\hline & Mean & 3.902 & 4.3488 & 4.617 & 4.739 & 4.889 & 4.803 & 27.3 \\
\hline & Std. Error of Mean & .094 & .0842 & .1043 & .109 & .1 & .114 & .474 \\
\hline & Std. Deviation & 1.06 & .942 & 1.166 & 1.227 & 1.126 & 1.281 & 5.309 \\
\hline \multirow{4}{*}{51 - 70 years } & $\mathrm{N}$ & 129 & 129 & 129 & 129 & 129 & 129 & 129 \\
\hline & Mean & 3.511 & 3.841 & 4.211 & 4.35 & 4.57 & 4.548 & 25.034 \\
\hline & Std. Error of Mean & .106 & .09 & .105 & .115 & .12 & .12 & .509 \\
\hline & Std. Deviation & 1.204 & 1.03 & 1.194 & 1.316 & 1.363 & 1.364 & 5.792 \\
\hline
\end{tabular}


Table 3. Level of length of relationship, desire, arousal, lubrication, orgasm, satisfaction, pain and overall FSFI scores.

\begin{tabular}{|c|c|c|c|c|c|c|c|c|}
\hline & & Desire & Aurousal & Lubrication & Orgasm & Satisfaction & Pain & FSFI \\
\hline \multirow{4}{*}{0 - 5 years } & $\mathrm{N}$ & 57 & 57 & 57 & 57 & 57 & 57 & 57 \\
\hline & Mean & 4.105 & 4.5737 & 4.694 & 4.722 & 4.982 & 5.08 & 28.159 \\
\hline & Std. Error of Mean & .148 & .131 & .164 & .168 & .147 & .132 & .7 \\
\hline & Std. Deviation & 1.121 & .99 & 1.241 & 1.274 & 1.111 & 1.002 & 5.286 \\
\hline \multirow{4}{*}{$6-10$ years } & $\mathrm{N}$ & 38 & 38 & 38 & 38 & 38 & 38 & 38 \\
\hline & Mean & 3.963 & 4.3263 & 4.61 & 4.631 & 4.789 & 4.789 & 27.11 \\
\hline & Std. Error of Mean & .197 & .16 & .205 & .226 & .224 & .226 & .951 \\
\hline & Std. Deviation & 1.22 & .987 & 1.264 & 1.396 & 1.38 & 1.393 & 5.864 \\
\hline \multirow{4}{*}{11 - 19 years } & $\mathrm{N}$ & 46 & 46 & 46 & 46 & 46 & 46 & 46 \\
\hline & Mean & 3.952 & 4.2522 & 4.643 & 4.9565 & 4.782 & 4.869 & 27.456 \\
\hline & Std. Error of Mean & .133 & .16 & .16 & .165 & .194 & .179 & .737 \\
\hline & Std. Deviation & .908 & 1.086 & 1.089 & 1.12 & 1.319 & 1.217 & 5.001 \\
\hline \multirow{4}{*}{20 - 29 years } & $\mathrm{N}$ & 75 & 75 & 75 & 75 & 75 & 75 & 75 \\
\hline & Mean & 3.56 & 4.036 & 4.384 & 4.421 & 4.65 & 4.576 & 25.628 \\
\hline & Std. Error of Mean & .128 & .127 & .144 & .148 & .152 & .164 & .691 \\
\hline & Std. Deviation & 1.113 & 1.103 & 1.255 & 1.285 & 1.316 & 1.422 & 5.991 \\
\hline \multirow{4}{*}{30 - 52 years } & $\mathrm{N}$ & 68 & 68 & 68 & 68 & 68 & 68 & 68 \\
\hline & Mean & 3.502 & 3.811 & 4.076 & 4.235 & 4.588 & 4.282 & 24.497 \\
\hline & Std. Error of Mean & .143 & .117 & .136 & .15 & .151 & .168 & .648 \\
\hline & Std. Deviation & 1.184 & .967 & 1.121 & 1.244 & 1.248 & 1.387 & 5.346 \\
\hline
\end{tabular}

\section{Discussion}

A mean index of 27.37 sexual function for the group of women with normal BMI and 26.35 in overweight women was found, with no significant difference. However, considering the scores that define sexual dysfunction, the overweight group shows a slight disadvantage that may have alterations in sexual function. This result is consistent with those described in the research of Sacomori, Cardoso, Souza, Poto, \& Cardoso (2013), which found no significant difference in the scores for sexual function among women with normal BMI, overweight and obesity. The results in the research of Silva Rego, Galvão, Florencio, Cavalcante (2012) indicates a prevalence of increased risk for sexual dysfunction of $78 \%$ for overweight and obese women.

Some authors claim that both overweight and obese woman has increased production of sex hormones which could increase both the desire and sexual function. However this increase in hormone production was not confirmed by the research of Carrilho (2011), which measured the serum concentrations of steroid hormones (cortisol, estradiol and dehydroepiandrosterone-DHEA) and evaluated the presence of sexual dysfunction using the FSFI questionnaire in obese women, with no association between sexual dysfunction, hormone levels and obesity was found.

Thus, the results of the research indicate that obese and overweight women do not have a higher amount of sex hormones. Furthermore, the group with normal BMI had higher Desire and Lubrication scores than the overweight group. These findings corroborate those found by Silva et al. (2012) and Carrilho (2011), which the score of desire was also pointed to be higher in people with normal BMI than in overweight ones.

However, as in the present study measurements of sex hormones between groups were not made, it is not possible to assert that the statistical differentiation in rates of sexual function is due to the similarity between the levels of sex hormones in overweight and normal BMI women. Perhaps the reasons why these women do not have better rates of sexual function are related to other variables such as cultural factors-how each population deals with sexuality, the length of relationship and body image.

Otero, Fernandez and Castro (2003) conducted a study with 325 women, analyzing the following variables: fear of putting on weight, body dissatisfaction, physical attractiveness and self-esteem. The researchers found a 
positive relationship on sexual activity; however, they found no relationship between body mass index, body image distortion and expression of sexuality. The results of this study indicated that variables such as age and length of relationship were more relevant to changes in sexual function index than the differences between normal BMI and overweight.

The results showed that women under 40 years old had significantly higher FSFI scores with higher levels of desire, arousal, lubrication and satisfaction than women who were over 40 years, indicating that women over 40 years have a higher risk of experiencing sexual dysfunction. This suggests that women over 40 years, as they are approaching the climacteric period marked by a series of changes caused mainly by falling estrogen levels, are more likely to report impairment of the urogenital tract such as urethral syndrome, the increase of urinary infections frequency, urinary urgency, dyspareunia, and vaginal dryness with important repercussions in the sexual sphere of women (De Lorenzi, Danelon, Saciloto, \& Padilla Jr, 2005; Lopes, 2003); (Nijland et al., 2008). In addition, there is also skin aging caused by the collagen reduction and the tendency of accumulating fat which affects the self-image, contributing to lower self-esteem and even the decline in sexual desire (De Lorenzi et al., 2005).

When the FSFI score is analyzed considering the length of marriage, the results showed that women who have been married for less time had higher FSFI scores than the ones who have been married longer, and this difference was statistically significant in both with normal BMI and the overweight groups.

Studies by Anthony Smith et al. (2011) about sexual satisfaction involving the importance of desire in sexual frequency in Australian heterosexual couples, found a positive relationship between the frequency of sex and overall sexual satisfaction. Considering men, the ones who tend to want sex more often than women. Among couples, the frequency of sex tends to decrease over time.

These results are consistent with the findings of Fisher et al. (2002) who point out that there is a sophisticated neural phylogenetic circuitry that subsidize the different behavioural responses depending on each stage the relationship is, which is also related to sexual hormones.

Short-term couples are probably still on the stage of passion, which lasts on average between 18 months to 3 years. This stage has the obsession with the partner as one of its main characteristic, which makes couples spend more time exploring the relationship. In this stage, besides the couples explore the relationship more they probably feel more desire (and seek sex more often) because they are experiencing lots of dopamine, which stimulates the production of testosterone. Such hypotheses may explain why the couples in this study-short-term ones, have better sexual function.

Considering the participants of this study, the relationship found between level of sexual function and length of relationship, indicated a decrease in sexual function in long-term relationships. In these relationships we found that the FSFI levels decreased to 24.49, which indicates possible sexual dysfunction in this group. Some specificities in neural attachment system, proposed by Fisher (2004), make us assume that the couples who are experiencing them are more likely to express sexual dysfunctions. As these neural systems do not need to occur in the following order (lust, passion and attachment) and may even occur simultaneously (Fisher, 2004), attachment need not necessarily be associated with good sexual performance with the partner not the satisfaction relationship. If the stage of attachment in general is the last stage in a relationship, then we can assume that long-term couples may have a strong attachment, which does not imply the existence of a good sexual function. Furthermore, hormones related to sex drive as estrogen and testosterone concentrations are lower during this phase (Fisher, 2000; Fisher, 2004; Fisher et al., 2002). In addition, one of the main consequences of the attachment between couples is increasing exploration environments unrelated to the relationship, which can decrease the frequency of sexual activity among couples (Fisher, 2004; Rebello, 2012). Sexual activity is one of the variables responsible for increasing testosterone levels (Nelson, 2011), and if testosterone decreases, we can assume that these couples have a higher propensity to sexual dysfunction at least on the desire level.

Moreover, the passion stage ends in long-term relationships, moment in which couples spend less time on sexual activity and more time raising children and concerns about the welfare of family and the marriage itself. The presence of the partner in everyday life becomes more important than the sexual satisfaction that she/he promotes.

Fisher (2004) also hypothesizes that humans have a propensity to maintain serial monogamy. Serial monogamy happens when the couple stays together for a period of time needed to grow their children until their basic neuromotors functions are developed, and if the relationship has become unsatisfactory, it can be undone, the moment which she/he can engage in a new relationship. If couples have propensity for serial monogamy it may 
be hypothesized that many couples keep long-term marriages due to other variables—not only love, but also cultural forces. This hypothesis supports the idea that there is a huge probability of long-term couples express sexual dysfunction due to a other variables.

\section{Conclusion}

The analysis showed the rate of 27.37 of sexual function for the group of women with normal BMI and 26.35 in overweight women, showing no sexual dysfunction considering the FSFI in both groups, according to parameters established by the literature, or, that in this study the sexual dysfunction was not controlled by the normal or overweight BMI factors. However, the rate of sexual function is controlled by factors such as age and length of relationship, in which the younger married women and short-term married women (regardless of age) had better sexual function index compared to older ones and long-term married women (regardless of age), where higher scores were in the domains of desire, arousal and satisfaction.

\section{Acknowledgements}

The authors express their gratitude to Federal University of Pará (PROPESP/FADESP) for the financial support on this publication, and to their colleagues from Grupo de Estudos Avançados em Psicologia Evolucionista (GEAPE http://www.geape.ufpa.br/).

\section{References}

Abdo, C. H. N. (2004). Estudo da Vida Sexual do Brasileiro. São Paulo: Editora Bregantini.

Abdo, C. N., \& Fleury, H. J. (2006). Aspectos diagnósticos e terapêuticos das disfunções sexuais femininas. Revista de Psiquiatria Clínica, 33, 162-167. http://dx.doi.org/10.1590/S0101-60832006000300006

Smith, A., Lyons, A., Ferris, J., Richters, J., Pitts, M., Shelley, J., \& Simpson, J. M. (2011). Sexual and Relationship Satisfaction among Heterosexual Men and Women: The Importance of Desired Frequency of Sex. Journal of Sex \& Marital Therapy, 37, 104-115. http://dx.doi.org/10.1080/0092623X.2011.560531

Bajos, N., Wellings, K., Laborde, C., \& Moreau, C. (2010). Sexuality and Obesity, a Gender Perspective: Results from French National Random Probability Survey of Sexual Behaviours. BMJ, 340, c2573. http://dx.doi.org/10.1136/bmj.c2573

Barroqueiro, R. S. B., Araújo, F. L. S. M., Barroqueiro, E. S. B., Araújo, G. F., \& Garcia, J. B. S. (2012). Função sexual feminina, sintomas de ansiedade e depressão em mulheres após cirurgia bariátrica. Revista Brasileira de Ciências Médicas e da Saúde, 14, 60-67.

Brill, M. (2004). Antidepressants and Sexual Dysfunction. Sexuality, Reproduction \& Menopause, 2, 35-40. http://dx.doi.org/10.1016/j.sram.2004.02.006

Buss, D. M., \& Shackelford, T. K. (2008). Attractive Women Want It All: Good Genes, Economic Investment, Parenting Proclivities, and Emotional Commitment. Evolutionary Psychology, 6, 134-146.

Carrilho, J. P. F. (2011). Disfunção sexual feminina e níveis dos hormônios esteroidais em mulheres obesas atendidas no ambulatório de ciurgia bariátrica do Hospital Universitário Onofre Lopes em Natal/RN. http://repositorio.ufrn.br:8080/jspui/bitstream/1/7572/1/PauloJFC_DISSERT.pdf

De Lorenzi, R. S., Danelon, C., Saciloto, B., \& Padilha Jr., I. (2005). Predicting Factors of Climacteric Symptoms. Revista Brasileira de Ginecologia e Obstetrícia, 27, 7-11.

Erenel, A. S., \& Kiline, F. N. (2013) Does Obesity Increase Sexual Dysfunction in Women? Sexuality and Disability, 31, 5362. http://dx.doi.org/10.1007/s11195-012-9274-4

Ferreira, A. L. C. G., Souza, A. I., \& Amorim, M. M. R. (2007). Prevalência das disfunções sexuais femininas em clínica de planejamento familiar de um hospital escola no Recife, Pernambuco. Revista Brasileira de Saúde Materno Infantil, 7, 143-150. http://dx.doi.org/10.1590/S1519-38292007000200004

Fisher, H. (1995). Anatomia do amor: A história natural da monogamia, do adultério e do divórcio. Rio de Janeiro: Eureka.

Fisher, H. (1998). Lust, Attraction and Attachment in Mammalian Reproduction. Human Nature, 9, 23-52. http://dx.doi.org/10.1007/s12110-998-1010-5

Fisher, H. (2000). Lust, Attraction, Attachment: Biology and Evolution of the Three Primary Emotions Systems for Mating, Reproduction and Parenting. Journal of Sexual Education and Therapy, 25, 1.

Fisher, H. (2004). Why We Love: The Nature and Chemistry of Romantic Love. New York: Henry Holt and Company Fisher.

Fisher, H., Aron, A., Mashek, D., Li, H., Strong, G., \& Brown, L. (2002). The Neural Mechanisms of Mate Choice: A Hy- 
pothesis. Neuroendocrinology Letters, 23, 92-97.

Gangestad, S. W., Haselton, M. G., \& Buss, D. M. (2006). Toward an Integrative Understanding of Evoked and Transmitted Culture: The Importance of Specialized Psychological Design. Psychological Inquiry, 17, 138-151. http://dx.doi.org/10.1207/s15327965pli1702_3

Hentschel, H., Alberton, D., Capp, E., Goldim, J. R., \& Passos, E. (2007). Validation of the Female Sexual Function Index (FSFI) for Portuguese Language. Revista do Hospital de Clínicas de Porto Alegre, 27, 10-14.

Huang, A. J., Stewart, A. L., Hernandez, A. L., Shen, H., \& Leslee, L. (2009). Sexual Function among Overweight and Obese Women with Urinary Incontinence in a Randomized Controlled Trial of an Intensive Behavioral Weight Loss Intervention. Journal of Urology, 181, 2235-2242. http://dx.doi.org/10.1016/j.juro.2009.01.046

Kaplan, H. S. (1981). The New Sex Therapy. Active Treatment of Sexual Dysfunctions. New York: Brunner/Mazel.

Kopelman, P. G. (1994). Investigation of Obesity. Clinical Endocrinology, 41, 703-708. http://dx.doi.org/10.1111/j.1365-2265.1994.tb02781.x

Lagergren, J., Mattsson, F., \& Nyrén, O. (2014). Gastroesophageal Reflux Does Not Alter Effects of Body Mass Index on Risk of Esophageal Adenocarcinoma. Clinical Gastroenterology and Hepatology, 12, 45-51. http://dx.doi.org/10.1016/j.cgh.2013.07.027

Laumann, E. O., Paik, A., \& Rosen, R. C. (1999). Sexual Dysfunction in the United States: Prevalence and Predictors. JAMA, 281, 537-544. http://dx.doi.org/10.1001/jama.281.6.537

Lippa, R. A. (2007). The Preferred Traits of Mates in a Cross-National Study of Heterosexual and Homosexual Men and Women: An Examination of Biological and Cultural Influences. Archives of Sexual Behavior, 36, 193-208. http://dx.doi.org/10.1007/s10508-006-9151-2

Liu, C. (2003). Does Quality of Marital Sex Decline With Duration? Archives of Sexual Behavior, 32, 55-60. http://dx.doi.org/10.1023/A:1021893329377

Lopes, G. P. (2003). Sexualidade: Fisiopatologia, diagnóstico e tratamento. In C. E. Fernandes (Ed.), Menopausa e tratamento (pp. 117-124). São Paulo: Editora Segmento.

Marazziti, D., Akiskal, H. S., Rossi, A., \& Cassano, G. B. (1999). Alteration of the Platelet Serotonin Transporter in Romantic Love. Psychological Medicine, 29, 741-745. http://dx.doi.org/10.1017/S0033291798007946

de Mendonça, C. R., Silva, T. M., Arrudai, J. T., García-Zapata, M. T. A., \& do Amaral, W. N. (2012). Função sexual feminina: Aspectos normais e patológico, prevalência no Brasil, diagnóstico e tratamento. Femina, 40, 195-202.

Morotti, E., Bataglia, B., Paradisi, R., Persico, N., Zampieri, M., Venturoli, S., \& Bataglia, C. (2012). Body Mass Index, Stunkard Figure Rating Scale and Sexuality in Young Italian Women: A Pilot Study. Journal of Sexual Medicine, 10, 1034-1043. http://dx.doi.org/10.1111/jsm.12045

Mulhall, J., King, R., Glina, S., \& Hvidsten, K. (2008). Importance of and Satisfaction with Sex among Men and Women Worldwide: Results of the Global Better Sex Survey. Journal of Sexual Medicine, 5, 788-795.

http://dx.doi.org/10.1111/j.1743-6109.2007.00765.x

Nelson, R. J. (2011). An Introduction to Behavioral Endocrinology (4th ed.). Sunderland, MA: Sinauer Associates, Inc. Publishers.

Nijland, E. A., Weijmar, W. C., Nathorst-Boös, J., Helmond, F. A., Van Lunsen, R. H., Palacios, S., Norman, R. J., Mulder, R. J., Davis, S. R., \& Study Investigators (2008). Tibolone and Transdermal E2/NETA for the Treatment of Female Sexual Dysfunction in Naturally Menopausal Women: Results of a Randomized Active-Controlled Trial. Journal of Sexual Medicine, 5, 646-656.

Otero, M. C., Fernandez, M. L., \& Castro, Y. R. (2003). Influencia de la imagen corporal y la autoestima en la experiencia sexual de estudiantes universitarias sin trastornos alimentarios. International Journal of Clinical and Health Psychology, 4, 357-370.

Piassaroli, V. P., Hardy, E., Andrade, N. F., Ferreira, N. O., \& Osis, M. J. D. (2010). Treinamento dos músculos do assoalho pélvico nas disfunções sexuais femininas. Revista Brasileira de Ginecologia e Obstetrícia, 32, 234-240. http://dx.doi.org/10.1590/S0100-72032010000500006

Rebello, K. S. S. (2012). Qualidade da relação conjugal: Uma avaliação dos casais residentes no Pará. Dissertação de Mestrado, Belém: Universidade Federal do Pará, PA. http://www.geape.ufpa.br/Keila\%20Rebello\%20-\%20disserta\%C3\%A7\%C3\%A30\%20UFPA.pdf

Sacomori, C., Cardoso, F. L., Souza, A. C. S., Poto, I. P., \& Cardoso, A. A. (2013). Relação entre características antropométricas e função sexual feminina. Revista Brasileira de Ciência e, 21, 116-122.

Silva, B. M., Rêgo, L. M., Galvão, M. A., Florêncio, T. M. M. T., \& Cavalcante, J. C. (2012). Incidência de disfunção sexual em pacientes com obesidade e sobrepeso. Revista do Colégio Brasileiro de Cirurgiões, 40, 196-202. http://dx.doi.org/10.1590/S0100-69912013000300006 
Sousa, R., Sousa, E., \& Silva, J. (2000). Fidedignidade do teste-reteste na aplicação do Índice Menopausal de Blatt e Kupperman. Revista Brasileira de Ginecologia e Obstetrícia, 22, 481-487. http://dx.doi.org/10.1590/S0100-72032000000800003

Vilas-Boas Sartori, D., De Souza, J. P., \& Carneiro, P. R. (2011). A influência da obesidade na musculatura do assoalho pélvico em mulheres continentes. Ensaios e Ciências, 15, 9-23.

Wiegel, M., Meston, C., \& Rosen, R. (2005). The Female Sexual Function Index (FSFI): Cross-Validation and Development of Clinical Cutoff Scores. Journal of Sex \& Marital Therapy, 31, 1-20. http://dx.doi.org/10.1080/00926230590475206

World Health Organization (2014). Controlling the Global Obesity Epidemic [Web log post]. http://www.who.int/nutrition/topics/obesity/en/ 


\section{Appendix}

\section{Female Sexual Function Index (FSFI)}

Subject Identifier

Date

INSTRUCTIONS: These questions ask about your sexual feelings and responses during the past 4 weeks. Please answer the following questions as honestly and clearly as possible. Your responses will be kept completely confidential. In answering these questions the following definitions apply:

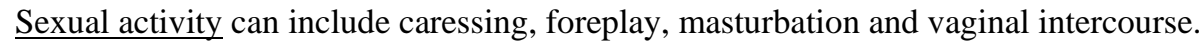

Sexual intercourse is defined as penile penetration (entry) of the vagina.

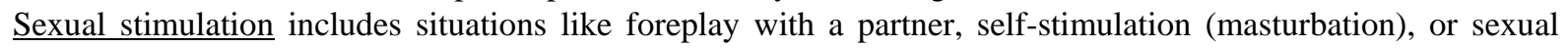
fantasy.

\section{CHECK ONLY ONE BOX PER QUESTION.}

Sexual desire or interest is a feeling that includes wanting to have a sexual experience, feeling receptive to a partner's sexual initiation, and thinking or fantasizing about having sex.

1. Over the past 4 weeks, how often did you feel sexual desire or interest?

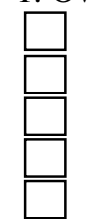

Almost always or always

Most times (more than half the time)

Sometimes (about half the time)

A few times (less than half the time)

Almost never or never

2. Over the past 4 weeks, how would you rate your level (degree) of sexual desire or interest?

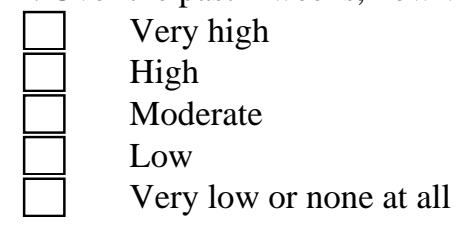

Sexual arousal is a feeling that includes both physical and mental aspects of sexual excitement. It may include feelings of warmth or tingling in the genitals, lubrication (wetness), or muscle contractions.

3. Over the past 4 weeks, how often did you feel sexually aroused ("turned on") during sexual activity or intercourse?

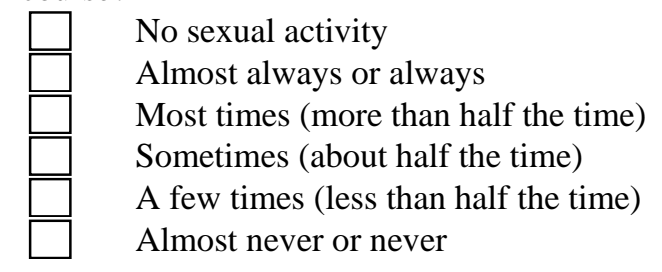

4. Over the past 4 weeks, how would you rate your level of sexual arousal ("turn on”) during sexual activity or intercourse?

\begin{tabular}{|l|l}
\hline & No sexual activity \\
\hline \hline & Very high \\
\hline$\square$ & High \\
& Moderate \\
\hline \hline & Low \\
\hline$\square \quad$ Very low or none at all
\end{tabular}


5. Over the past 4 weeks, how confident were you about becoming sexually aroused during sexual activity or intercourse?
\begin{tabular}{l}
$\square$ \\
$\square$ \\
\hline$\square$ \\
\hline$\square$ \\
\hline$\square$
\end{tabular}
No sexual activity Very
high confidence High
confidence Moderate
confidence Low
confidence

6. Over the past 4 weeks, how often have you been satisfied with your arousal (excitement) during sexual activity or intercourse?

No sexual activity

Almost always or always

Most times (more than half the time)

Sometimes (about half the time)

A few times (less than half the time)

Almost never or never

7. Over the past 4 weeks, how often did you become lubricated ("wet”) during sexual activity or intercourse?

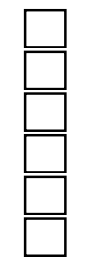

No sexual activity

Almost always or always

Most times (more than half the time)

Sometimes (about half the time)

A few times (less than half the time)

Almost never or never

8. Over the past 4 weeks, how difficult was it to become lubricated ("wet”) during sexual activity or intercourse?

No sexual activity

Extremely difficult or impossible

Very difficult

Difficult

Slightly difficult

Not difficult

9. Over the past 4 weeks, how often did you maintain your lubrication (“wetness”) until completion of sexual activity or intercourse?

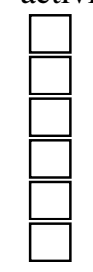

No sexual activity

Almost always or always

Most times (more than half the time)

Sometimes (about half the time)

A few times (less than half the time)

Almost never or never

10. Over the past 4 weeks, how difficult was it to maintain your lubrication ("wetness") until completion of sexual activity or intercourse?

No sexual activity

Extremely difficult or impossible

Very difficult

Difficult

Slightly difficult

Not difficult 
11. Over the past 4 weeks, when you had sexual stimulation or intercourse, how often did you reach orgasm (climax)?

No sexual activity

Almost always or always

Most times (more than half the time)

Sometimes (about half the time)

A few times (less than half the time)

Almost never or never

12. Over the past 4 weeks, when you had sexual stimulation or intercourse, how difficult was it for you to reach orgasm (climax)?

No sexual activity

Extremely difficult or impossible

Very difficult

Difficult

Slightly difficult

Not difficult

13. Over the past 4 weeks, how satisfied were you with your ability to reach orgasm (climax) during sexual activity or intercourse?
No sexual activity
Very satisfied
Moderately satisfied
About equally satisfied and dissatisfied
Moderately dissatisfied
Very dissatisfied

14. Over the past 4 weeks, how satisfied have you been with the amount of emotional closeness during sexual activity between you and your partner?

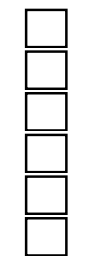
No sexual activity
Very satisfied
Moderately satisfied
About equally satisfied and dissatisfied
Moderately dissatisfied
Very dissatisfied

15. Over the past 4 weeks, how satisfied have you been with your sexual relationship with your partner?

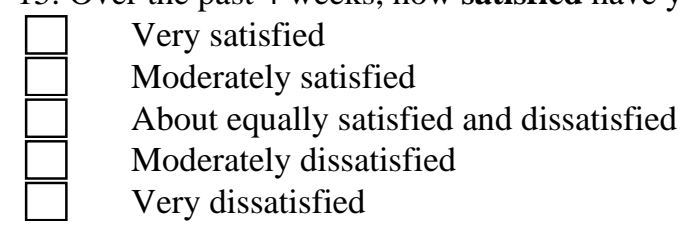

16. Over the past 4 weeks, how satisfied have you been with your overall sexual life?

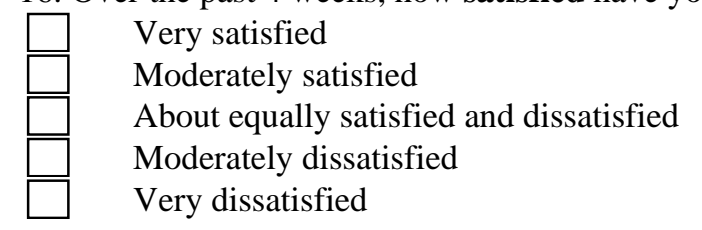

17. Over the past 4 weeks, how often did you experience discomfort or pain during vaginal penetration?

Did not attempt intercourse

Almost always or always 
Most times (more than half the time)

Sometimes (about half the time)

A few times (less than half the time)

Almost never or never

18. Over the past 4 weeks, how often did you experience discomfort or pain following vaginal penetration?

Did not attempt intercourse

Almost always or always

Most times (more than half the time)

Sometimes (about half the time)

A few times (less than half the time)

Almost never or never

19. Over the past 4 weeks, how would you rate your level (degree) of discomfort or pain during or following vaginal penetration?

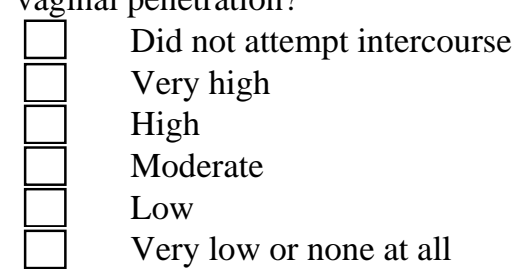

Thank you for completing this questionnaire. 
Scientific Research Publishing (SCIRP) is one of the largest Open Access journal publishers. It is currently publishing more than 200 open access, online, peer-reviewed journals covering a wide range of academic disciplines. SCIRP serves the worldwide academic communities and contributes to the progress and application of science with its publication.

Other selected journals from SCIRP are listed as below. Submit your manuscript to us via either submit@scirp.org or Online Submission Portal.
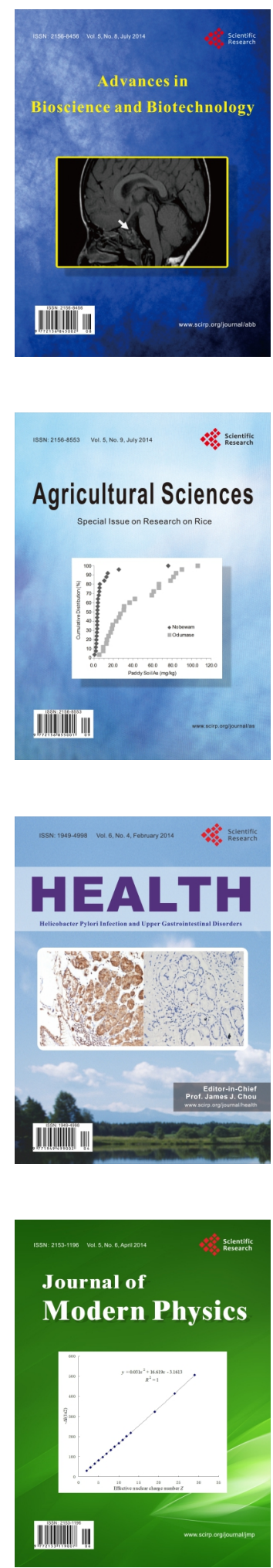
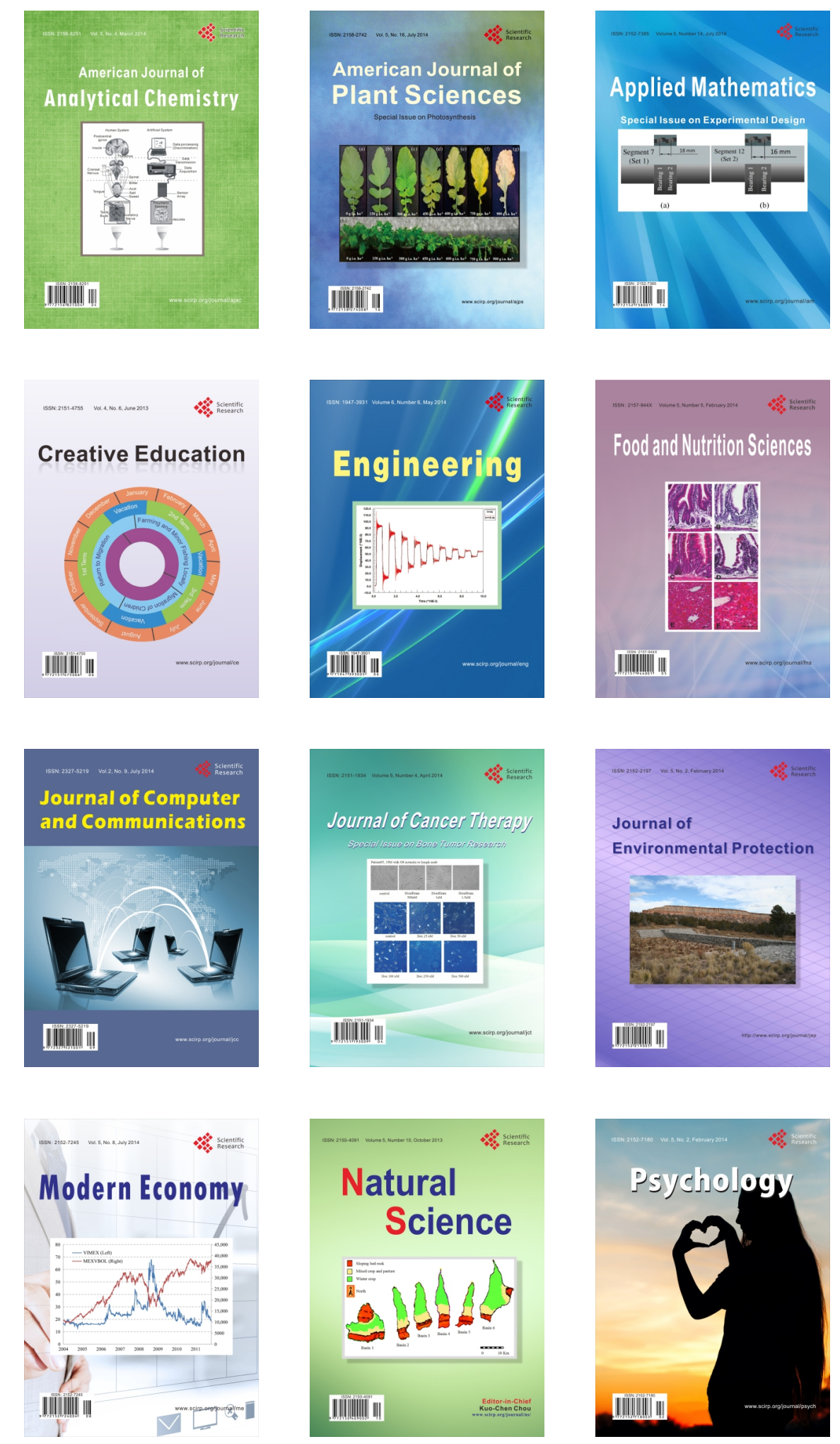